\title{
Fusion Rates with Autologous Bone Grafts in Pediatric Patients Undergoing Posterior Cervical Spine Fusion
}

\author{
Laura Nanna Lohkamp" ${ }^{*}$, James Drake, Peter Dirks, James Rutka, Abhaya V Kulkarni, George M Ibrahim, \\ Michael David Taylor ${ }^{1}$, David Lebel and Reinhard Dirk Zeller ${ }^{2}$
}

${ }^{1}$ Division of Neurosurgery, The Hospital for Sick Children, Canada

${ }^{2}$ Division of Orthopedic Surgery, The Hospital for Sick Children, Canada

Submission: April 21, 2021; Published: May 10, 2021

*Corresponding author: Laura-Nanna Lohkamp, MD, MSc, The Hospital for Sick Children, 555 University Ave, Toronto, ON M5G 1X8, Canada

Abstract

Objective: Surgical management of cervical instability and obtaining solid bone fusion in children is technically challenging due to smaller and immature anatomy besides the lack of pediatric-adapted instrumentation. Optimizing fusion via additional bone grafting and postoperative HALO device application has been a topic of controversy. We describe our experience with posterior cervical spine fusion techniques and re-visit the role of autologous bone grafting.

Methods: We performed a retrospective chart review of children, who underwent rigid instrumentation and/or onlay bone graft fusion between 2008 and 2019. The primary outcome was solid bone fusion at 2 years after surgery. Secondary outcomes were neurological outcome and adverse events, including surgical and postoperative complications, graded according to the Spinal Adverse Events Severity System, version 2 (SAVES-V2).

Results: Twenty-one patients had a minimum follow up of 2 years (mean 4.65 years, range: 2.0 - 10.68 years), including 14 males and 7 females. The mean age at surgery was 8.4 years (median 8, range 0.7 - 14 years). Indications for surgical fusion were C1/2 instability, secondary instability after surgery, trauma and other etiologies. Seventeen patients underwent rigid instrumentation with application of autologous bone graft and 4 patients onlay bone graft fusion only. Thirteen patients underwent postoperative HALO vest application. Final solid bone fusion was achieved in 19 patients, including 2 with asymptomatic hardware failure. Nonunion and worsening junctional kyphosis required revision surgery in 2 patients. Neurological status remained unchanged postoperatively and at last follow-up. The surgical complication rate was $14 \%$, the overall complication rate $23 \%$ respectively.

Conclusion: Variable fusion techniques of the cervical spine can be safely performed and result in adequate fixation in children. Autologous bone grafting is substantially contributing to solid fusion while having a low morbidity profile.

Keywords: Posterior cervical spine instrumentation; Pediatric; Fusion; Bone graft; Autologous

Abbreviations: BMP: Bone Morphogenetic Proteins; CT: Computer Tomography; FU: Follow Up; MEPs: Motor Evoked Potentials; MRI: Magnet Resonance Imaging; PSIF: Posterior Spinal Instrumented Fusion; SSEPs: Somatosensory Evoked Potentials

\section{Introduction}

The quality of bone fusion is one of the most critical outcomes in the surgical management of cervical instability. It highly contributes to the rate of revision surgeries and overall long-term outcome [1,2]. Especially in children the surgical management of cervical instability and achieving solid fusion is technically challenging due to the age-dependent variation of anatomy and the lack of pediatric-adapted instrumentation hardware and tools $[3,4]$.

Importantly, the different subset of etiologies resulting in instability of the pediatric cervical spine comprise acquired, but also congenital, syndromic and developmental disorders, which differ from adult pathologies which are characterized by 
mostly degenerative and traumatic origins. Accordingly, surgical techniques transferred from adults to pediatrics required technical adjustments and flexibility in their application [4]. Given the growing and immature nature of the pediatric spine additional amendments are necessary in order to anticipate the variable anatomy and secondary adverse effects such as adjacent segment degeneration and reduced future growth, depending on the levels and length of the construct [5,6]. Different instrumentation techniques of the pediatric cervical spine have been described, including non-rigid techniques such as external fixation (HALOvest immobilization), variable techniques of internal fixation and onlay bone grafting only [2,7-9].

Supplemental measures of enhancing fusion include the postoperative application of an external HALO device as well as autologous bone grafting or the application of bone morphogenic protein combined with cancellous morselized allograft during the surgery [10]. Despite their assumed benefit of optimizing postoperative fusion, both of these techniques remain subject of a controversial discussion in previous outcome reports with respect to invasiveness, associated morbidity for autologous bone grafting, compliance and necessity for the external HALO device, respectively [11-15]. We describe our experience with posterior cervical spine fusion techniques in children and re-visit the role of autologous bone grafting.

\section{Clinical Material and Methods}

We performed a single center, retrospective observational study including pediatric patients with diagnosed cervical instability, who underwent a first time posterior cervical spinal instrumentation, combined anterior and posterior instrumentation and/or onlay bone graft fusion between January 1, 2008, and December 31, 2019, at the Hospital for Sick Children Toronto, Canada. Demographic, radiological, and clinical data were gathered through a retrospective chart review according to the following inclusion criteria:

a) Age $<18$ years at time point of surgery.

b) Cervical instability ( $\mathrm{x}$-ray, MRI, w/wo neurological deficit). c) Posterior spinal instrumented fusion (PSIF) or onlay bone graft fusion.

d) Follow-up $(\mathrm{FU})>2$ years.

Exclusion criteria were a follow-up period of less than 2 years as well as incomplete clinical and radiographic follow-up. Clinical characteristics, indications for fusion, neurological examination findings, and the use of external Halo traction or vest pre- and postoperatively were reviewed. The primary outcome was defined as presence of a solid bone fusion at 2 years after surgery on plain and dynamic x-ray films, whereas the secondary outcomes included type and number of revision surgeries, surgical complications and neurological outcome. The radiographic indices for a solid fusion were:

a) Presence of a solid fusion mass on x-ray posterior to the fused segments.

b) Absence of motion in dynamic x-rays.

c) Absence of signs for hardware failure (breakage, dislocation).

d) Absence of halo-sign as indicator for screw loosening.

Approval for the study was obtained from the University of Toronto Research Ethics Board and the study was conducted in accordance with ethics guidelines.

\section{Results}

Twenty-one out of 31 patients met the inclusion criteria and had a minimum follow up of 2 years (mean 4.65 years, range: 2.010.68 years). The remaining 10 patients had not completed the 2-year follow up at the time point of study submission. The sex distribution was 2:1, with 14 males and 7 females. The mean age at surgery was 8.4 years (median 8 years, range 0.7-14 years). Indications for surgical fusion were $\mathrm{C} 1 / 2$ instability ( 9 patients), secondary instability after tumor surgery ( 5 patients), trauma ( 2 patients) and other etiologies (5 patients). Importantly, most of the treated cervical instabilities occurred in a syndromic context (8 patients) and congenital disorders (2 patients), 48\% respectively. A detailed list of the patients' demographic data, their fusion levels and their pathologies are given in (Table 1).

Table 1: Overview of the patients' demographics, their underlying pathologies leading to cervical instability and the derived fusion levels.

\begin{tabular}{|c|c|c|c|c|c|c|c|}
\hline Case No. & $\begin{array}{c}\text { Age } \\
\text { (Years) }\end{array}$ & Sex & Diagnosis & $\begin{array}{c}\text { Pathology } \\
\text { Level }\end{array}$ & $\begin{array}{c}\text { Fusion } \\
\text { Level }\end{array}$ & Construct Notes & FU (Years) \\
\hline 1 & 8 & M & Down syndrome & OCI & OC-C2 & Posterior instrumented fusion & 4,9 \\
\hline 2 & 11 & M & Hurler syndrome & C1-3 & OC-C2 & Bone onlay only & 2 \\
\hline 3 & 0,7 & F & Hyperextension injury & C1/2 & C1-2 & Unilateral Magerl screw left & 2,6 \\
\hline 4 & 12 & M & Goldenhaar syndrome & OCI & OC-C4 & Posterior instrumented fusion & 5,1 \\
\hline 5 & 6 & F & Os odontoideum & C1/2 & C1-2 & Posterior instrumented fusion & 4,1 \\
\hline 6 & 9 & M & Spondyloepiphyseal dysplasia & C1/2 & C1-2 & Posterior instrumented fusion & 8,6 \\
\hline 7 & 6 & F & Down syndrome & C1/2 & C1-2 & Posterior instrumented fusion & 4,9 \\
\hline
\end{tabular}




\begin{tabular}{|c|c|c|c|c|c|c|c|}
\hline 8 & 6,5 & M & Hunter-Hurler Syndrome & C1/2 & C1-2 & Posterior instrumented fusion & 10,7 \\
\hline 9 & 11 & M & Aneurysmal bone cyst & C6 & C5-7 & Posterior instrumented fusion & 6,3 \\
\hline 10 & 14 & M & Os odontoideum & C1/2 & OC-C2 & Bone onlay only & 2,4 \\
\hline 11 & 2 & M & Klippel-Feil syndrome & C1/2 & OC-C3 & Bone onlay only & 4,1 \\
\hline 12 & 13 & F & Chordoma & C5/6 & C3-T1 & Posterior instrumented fusion & 3,9 \\
\hline 13 & 6 & F & Spondyloepiphyseal dysplasia & OC-C2 & OC-C2 & Bone onlay only & 3,7 \\
\hline 14 & 8 & M & Os odontoideum & C1/2 & OC-C4 & Posterior instrumented fusion & 2,2 \\
\hline 15 & 7 & M & Os odontoideum & C1/2 & OC-C4 & Posterior instrumented fusion & 3,3 \\
\hline 16 & 10 & F & Aneurysmal bone cyst & C4 & C3-5 & Posterior instrumented fusion & 7,6 \\
\hline 17 & 5 & F & Osteoblastoma & C2/3 & C2-C4 & Posterior instrumented fusion & 3,4 \\
\hline 18 & 13 & M & Burst fracture & C4 & C3-5 & Combined anterior and posterior fusion & 2,5 \\
\hline 19 & 8 & M & Aneurysmal bone cyst & C4 & C3-5 & Posterior instrumented fusion & 3,6 \\
\hline 20 & 9 & M & Klippel-Feil syndrome & C5-7 & OC-T5 & Posterior instrumented fusion & 6,2 \\
\hline 21 & 12 & M & Klippel-Feil syndrome & C7/T1 & OC-T3 & Posterior instrumented fusion & 5,5 \\
\hline
\end{tabular}

\section{Treatment overview}

The diagnosis of cervical instability was determined by assessing a combination of plain and dynamic x-ray studies and magnetic resonance images demonstrating significantly increased mobility in one or more of the three planes of movement (flexionextension, axial rotation, and lateral bending. Thin-cut computer tomography (CT) scans with 2D sagittal and coronal as well as 3D reconstructions were obtained pre-operatively for surgical planning with respect to the optimal fusion and instrumentation technique. Four patients underwent preoperative HALO traction in order to obtain a closed reduction in the context of subluxation or cervicothoracic dissociation.
Two of them underwent additional HALO vest application as well as 2 other patients with Down syndrome for primary preoperative stabilization. Sixteen patients were submitted to rigid posterior instrumentation and one patient combined anterior and posterior instrumentation, all with intraoperative application of autologous bone graft. We performed an onlay bone graft fusion only in 4 patients. The autologous bone graft was predominantly harvested from the iliac crest (17 patients), followed by the rib (2 patients) and local graft from the spinous processes (2 patients). All of the surgeries were performed with a rigid head fixation in the Mayfield clamp and under neuromonitoring including somatosensory evoked potentials (SSEPs) and motor evoked potentials (MEPs).

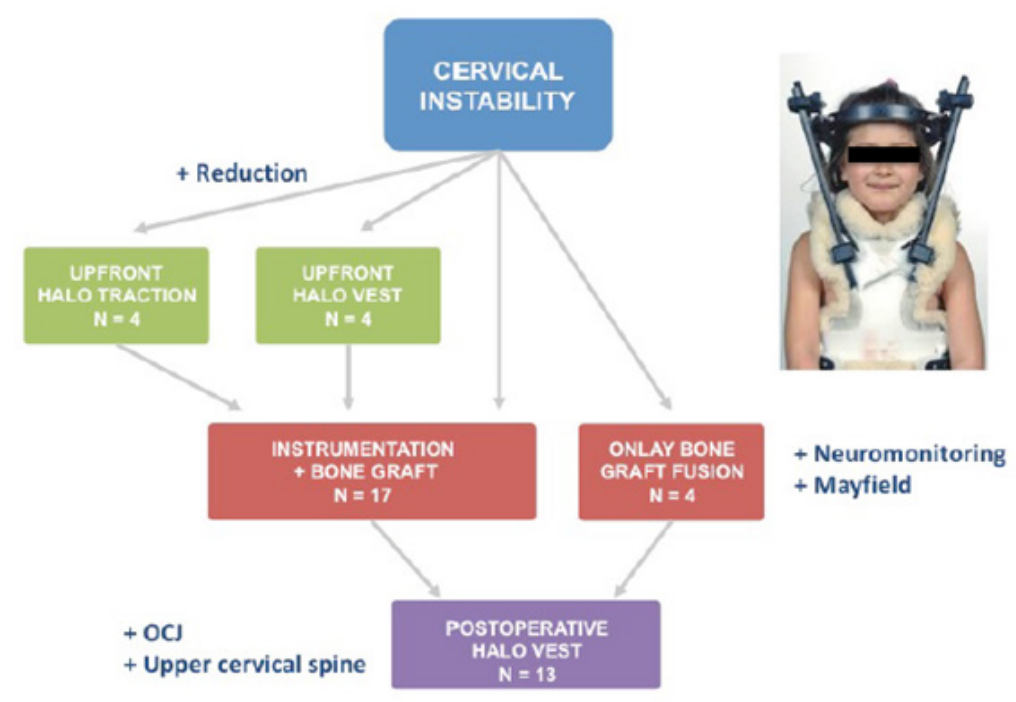

Figure 1: Schematic illustration of the treatment paths within the patient cohort, indicating the sequential procedures and measures applied. 
Postoperative HALO vest application was performed in 13 patients, including 8 syndromic patients, 2 patients with a congenital disorder as well as one trauma patient with a severe hyperextension injury. The levels of fusion in all of these patients were located in the upper cervical spine at $\mathrm{C} 1 / 2$ or at the craniocervical junction, including the occiput as upper fixation point. All patients, who underwent posterior cervical fusion with onlay bone graft only were included in this group (Figure 1). The time period for postoperative HALO vest application ranged between 2 and 3 months.

\section{Primary outcome}

Solid bone fusion was confirmed radiographically via dynamic x-ray and computer tomography in 19 patients (90\%) at the 2-year follow-up, including 2 patients with asymptomatic hardware failure. One of them had a rod breakage on one side and the other one a questionable screw loosening, however a solid posterior bone fusion mass was present, and no motion observed in the dynamic x-rays. Nonunion and worsening junctional kyphosis required revision surgery in 2 patients at 5 and 6 months postoperative follow up.

One of these patients with Hurler syndrome had a previous bone onlay only fusion anticipating his small posterior elements, which did not permit primary instrumentation. He required augmentation of the autologous bone with additional grafting from the rib. A nine-month-old female developed a non-union with persistent atlantoaxial instability, equally requiring augmentation of the autologous bone graft and extension of her fusion to C3 (see case illustration, (Figure 2)). The rate of fusion failure in the early postoperative course was $10 \%$. Radiographic data on the fusion outcomes are shown in (Table 2).

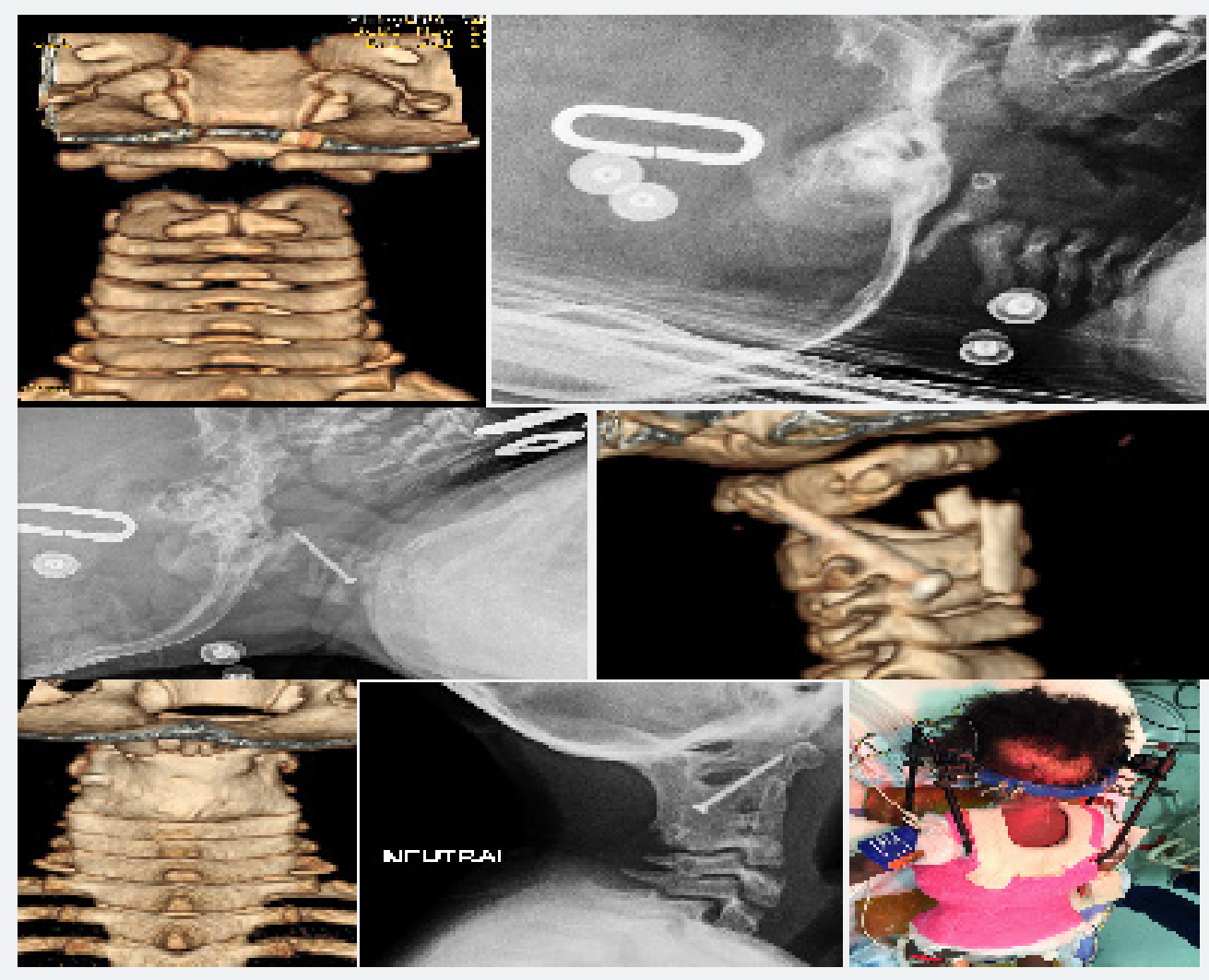

Figure 2: Case illustration: A 9-month-old female presented with a severe distraction injury due to hyperextension of her neck in the context of non-accidental injury, resulting in a C1/2 instability (Figure 2A, 2B). An initial external bracing treatment failed and surgical fusion was required. We performed a unilateral C1-2 transarticular screw fixation on the left side using a metacarpal screw and the Magerl technique given that her small anatomy of the right side did not favor any screw insertion. This was followed by application of autologous bone graft harvested from the right rib (Figure 2C). Postoperatively the patient was placed into a customized Minerva brace. At 5 months post-op a persisting non-union was observed, requiring further extension of the fusion to the occiput via augmentation of the autologous bone graft (Figure 2D). After the second surgery a HALO-vest was replaced by a HALO-cast as the vest was poorly fitting and did not provide enough stability, followed by a final replacement by a Minerva cast due to repeat pin site infections (Figure 2E). The final x-rays and CT at the 2-year follow-up demonstrated successful fusion with presence of a solid bone mass posteriorly reaching the occiput (Figure 2F, 2G). 
Table 2: Overview of radiographic outcome parameters and complications. The severity of complications is graded according to the Spinal Adverse Events Severity System, version 2 (SAVES-V2).

\begin{tabular}{|c|c|c|c|c|c|c|}
\hline $\begin{array}{l}\text { Case } \\
\text { No. }\end{array}$ & $\begin{array}{l}\text { Dynamic X-ray - } \\
\text { Motion (yes/no) }\end{array}$ & $\begin{array}{c}\text { Halo Sign (yes/ } \\
\text { no) }\end{array}$ & $\begin{array}{l}\text { Continuous } \\
\text { Fusion Mass }\end{array}$ & $\begin{array}{c}\text { Hardware Failure } \\
\text { (yes/no) }\end{array}$ & Complication & SAVES-V2 Grade \\
\hline 1 & $\mathrm{n}$ & $\mathrm{n}$ & Present & $\mathrm{n}$ & & \\
\hline 2 & $\mathrm{n}$ & Bony fusion only & Non-union & Bony fusion only & Junctional kyphosis & 3 \\
\hline 3 & $\mathrm{n}$ & $\mathrm{n}$ & Non-union & $\mathrm{n}$ & $\begin{array}{l}\text { Persistant atlantoaxial } \\
\text { instability }\end{array}$ & 3 \\
\hline 4 & $\mathrm{n}$ & $\mathrm{n}$ & Present & y (broken rod) & Epidural hematoma & 3 \\
\hline 5 & $\mathrm{n}$ & $\mathrm{n}$ & Present & y (C1 screw) & & \\
\hline 6 & $\mathrm{n}$ & $\mathrm{n}$ & Present & $\mathrm{n}$ & & \\
\hline 7 & $\mathrm{n}$ & $\mathrm{n}$ & Present & $\mathrm{n}$ & & \\
\hline 8 & $\mathrm{n}$ & $\mathrm{n}$ & Present & $\mathrm{n}$ & & \\
\hline 9 & $\mathrm{n}$ & $\mathrm{n}$ & Present & $\mathrm{n}$ & & \\
\hline 10 & $\mathrm{n}$ & Bony fusion only & Present & Bony fusion only & & \\
\hline 11 & $\mathrm{n}$ & Bony fusion only & Present & Bony fusion only & & \\
\hline 12 & $\mathrm{n}$ & $\mathrm{n}$ & Present & $\mathrm{n}$ & & \\
\hline 13 & $\mathrm{n}$ & Bony fusion only & Present & Bony fusion only & Halo pin loosening & 2 \\
\hline 14 & $\mathrm{n}$ & minimal & Present & $\mathrm{n}$ & Halo pin loosening & 2 \\
\hline 15 & $\mathrm{n}$ & $\mathrm{n}$ & Present & $\mathrm{n}$ & & \\
\hline 16 & $\begin{array}{l}\text { y (adjacent seg- } \\
\text { ment) }\end{array}$ & $\mathrm{n}$ & Present & $\mathrm{n}$ & & \\
\hline 17 & $\mathrm{n}$ & $\mathrm{n}$ & Present & $\mathrm{n}$ & & \\
\hline 18 & $\mathrm{n}$ & $\mathrm{n}$ & Present & $\mathrm{n}$ & & \\
\hline 19 & $\mathrm{n}$ & $\mathrm{n}$ & Present & $\mathrm{n}$ & & \\
\hline 20 & $\mathrm{n}$ & $\mathrm{n}$ & Present & $\mathrm{n}$ & & \\
\hline 21 & $\mathrm{n}$ & $\mathrm{n}$ & Present & $\mathrm{n}$ & & \\
\hline
\end{tabular}

\section{Secondary outcomes}

The neurological status of all patients remained unchanged postoperatively and at the last follow-up visit. There were no transient neurological deficits observed in the early postoperative course.

Non-fusion related complications were development of an epidural hematoma after HALO ring application in one patient, necessitating emergent surgical decompression. HALO vest adjustments requiring additional sedation occurred in 2 patients. One patient developed repeat pin site infections due to the lack of adequate care and required antibiotic treatment. None of the patients developed a primary surgical site infection or complications related to the bone graft site. The overall complication rate was $23 \%$, including the HALO vest adjustments and complications related to its placement and positioning. Complications and their grading according to the Spinal Adverse Events Severity System, version 2 (SAVES-V2) are indicated in (Table 2) [16].

\section{Discussion}

We have described our experience managing cervical instability of various etiologies in 21 children, undergoing surgical fusion with rigid instrumentation or bone onlay grafts only. All patients underwent autologous bone grafting during the index procedure and $90 \%$ were confirmed with a solid fusion at the 2-year follow up. Two patients required revision surgery due to non-union and junctional kyphosis, indicating temporary lack of solid fusion. However, solid fusion could be achieved after revision surgery with augmentation of the bone graft in both patients.

Multiple studies reported the use of autologous bone grafting and its impact on obtaining solid fusion $[11,12,17,18]$. Posterior iliac crest autograft is the preferred substrate for bone graft material, followed by rib graft in youngest children and after multiple fusion attempts. Despite its excellent structural support and its benefit on fusion outcome it remains controversially discussed in regard to morbidity and surgical site complications $[2,19]$. Several authors discuss a significant morbidity from the 
autograft harvest site, such as donor site pain, increased blood loss and infection risk, seroma formation, pelvic fracture, and the risk of peripheral nerve injury.

Moreover, it was experienced as a challenge to harvest and craft a well-fitting bone block from a small rib or thin iliac crest in children $[1,20,21]$. We did not observe any of these morbidities or complications in our cohort. From a technical perspective we equally did not face any challenges in harvesting the bone graft, which might be related to using autograft as a "gold-standard" during deformity surgeries in our institution. Other authors confirmed a clear superiority of autologous bone graft compared to allograft or bone morphogenetic proteins (BMP) and advocate for its continuous use [22,23].

A recent meta-analysis published by Reintjes et al. [20] assessed the fusion rates in 604 pediatric patients undergoing either posterior cervical or occipitocervical instrumented fusion with additional grafting of autologous bone in 539 and in 65 patients with application of allograft. Higher overall fusion rates were observed in the autologous compared to the allograft group (94\% vs $80 \%$ ) [20]. In our study autologous bone graft was applied to 21 patients, of which 2 demonstrated a shortterm postoperative fusion failure $(10 \%)$ resulting in a fusion rate of $90 \%$. These results are concordant with previous reports and confirm the benefit of autologous bone grafting with a low morbidity profile. Importantly, we could demonstrate overall good fusion results in patients with bone onlay graft only.

The 4 patients were 2, 6, 11 and 14 years old, suggesting that success of this technique is not necessarily restricted to a specific age group or younger children. However, randomized controlled trials are warranted in order to compare the efficiency and outcomes of rigid instrumentation versus onlay bone graft only. Another important point of discussion is the pre- and postoperative use of HALO devices. They were applied in the majority of our patients, 13 patients (62\%) respectively. The reasoning was either to achieve preoperative reduction or to facilitate postoperative fusion.

Latter one might be particularly at risk in patients with cerebral palsy, in syndromic and youngest patients, who might present with abnormal movements or compromised compliance. Furthermore, given the softer bone texture there is a higher complication rate related to implant pull-out in these pediatric patients. In this context HALO vest application after posterior cervical fusion has been shown to be beneficial. Moreover, we do think that fusions performed with onlay bone graft only mandate postoperative external stabilization in order to facilitate a solid bone fusion. Despite not having experienced many pin site infections, except in one patient, we confirm a higher complication rate in patients with HALO devices.

These are either related to readjustments, requiring most of the time sedation and complications that occurred during placement of the device per se. Although HALO devices are related to a higher complication profile, they outweighed in our patient cohort with many complex and syndromic patients the risk of implant pull-out and nonunion. Previous studies reported similar complications, but also an increased fusion rate in patients with postoperative HALO vest or Minerva cast application [24,25]. Thus, the indication for HALO devices needs to be adapted to the underlying pathology, degree of instability, levels of fusion and the compliance of the patient, outweighing its risks and benefits in a critical manner.

Limitations of the study are the small number of patients, especially in the onlay bone graft group as well as the confounding factor of not having a control group, undergoing rigid instrumentation without additional application of autologous bone graft.

\section{Conclusion}

In this study, we found that the variable fusion techniques of the pediatric cervical spine can be safely performed and represent an effective way to treat cervical instability in various pathologies and patient ages. The supplemental application of autologous bone graft increases the quality of fusion while having a low morbidity profile with respect to the grafting site. The use of postoperative HALO vest application can be advantageous in syndromic patients and those, who undergo fusion of the upper cervical spine and the craniocervical junction in order to enhance the construct stability and fusion onset. Further studies with larger patient numbers are required to confirm these findings.

\section{Acknowledgement}

We would like to thank our neuromonitoring and orthotics team for their cooperation and support in the clinical management of the reported patients.

\section{References}

1. Godzik J, Ravindra VM, Ray WZ, Schmidt MH, Bisson EF, et al. (2015) Comparison of structural allograft and traditional autograft technique in occipitocervical fusion: radiological and clinical outcomes from a single institution. J Neurosurg Spine 23(2): 144-152.

2. Groen JL, Peul WC, Pondaag W (2020) Fusion rates support wired allograft combined with instrumented craniocervical fixation in the paediatric population. Acta Neurochir 162(5): 985-991.

3. Karandikar M, Mirza SK, Song K, Yang T, Krengel WF, et al. (2012) Complex pediatric cervical spine surgery using smaller nonspinal screws and plates and intraoperative computed tomography. J Neurosurg Pediatr 9(6): 594-601.

4. Mendenhall S, Mobasser D, Relyea K, Jea A (2019) Spinal instrumentation in infants, children, and adolescents: a review. J Neurosurg Pediatrir 23(1): $1-15$

5. Goldstein HE, Neira JA, Banu M, Aldana PR, Braga BP, et al. (2018) Growth and alignment of the pediatric subaxial cervical spine following rigid instrumentation and fusion: a multicenter study of the Pediatric Craniocervical Society. J Neurosurg Pediatr 22(1): 81-88. 
6. Wang JC, Nuccion SL, Feighan JE, Cohen B, Dorey FJ, et al. (2001) Growth and development of the pediatric cervical spine documented radiographically. J Bone Joint Surg Am 83(8): 1212-1218.

7. Chamoun RB, Relyea KM, Johnson KK, Whitehead WE, Curry DJ, Luerssen TG, et al. (2009) Use of axial and subaxial translaminar screw fixation in the management of upper cervical spinal instability in a series of 7 children. Neurosurgery 64(4): 734-739.

8. Hillard VH, Fassett DR, Finn MA, Apfelbaum RI (2009) Use of allograft bone for posterior C1-2 fusion. J Neurosurg Spine 11(4): 396-401.

9. Hedequist DJ (2014) Modern posterior screw techniques in the pediatric cervical spine. World J Orthop 5(2): 94-99.

10. Kowalski RJ, Ferrara LA, Benzel EC (2001) Biomechanics of bone fusion. Neurosurg Focus 10(4): E2.

11. Anderson RC, Ragel BT, Mocco J, Bohman LE, Brockmeyer DL (2007) Selection of a rigid internal fixation construct for stabilization at the craniovertebral junction in pediatric patients. J Neurosurg 107(1 Suppl): 36-42.

12. Dickerman RD, Morgan JT, Mittler M (2005) Circumferential cervical spine surgery in an 18-month-old female with traumatic disruption of the odontoid and C3 vertebrae. Case report and review of techniques. Case report and review of techniques. Pediatr Neurosurg 41(2): 88-92.

13. Iyer RR, Tuite GF, Meoded A, Carey CC, Rodriguez LF (2017) A Modified Technique for Occipitocervical Fusion Using Compressed Iliac Crest Allograft Results in a High Rate of Fusion in the Pediatric Population. World Neurosurg 107: 342-350.

14. Brockmeyer DL, Sivakumar W, Mazur MD, Sayama CM, Goldstein HE, et al. (2018) Identifying Factors Predictive of Atlantoaxial Fusion Failure in Pediatric Patients: Lessons Learned From a Retrospective Pediatric Craniocervical Society Study. Spine 43(11): 754-760.

15. Pingarilho AR, Porto De Melo PM, Elbabaa SK (2018) Postoperative Immobilization following Occipitocervical Fusion in the Pediatric Population: Outcome Evaluation and Review of Literature. Pediatr Neurosurg 53(2): 81-88.

16. Rampersaud YR, Anderson PA, Dimar JR, Fisher CG (2016) Spinal
Adverse Events Severity System, version 2 (SAVES-V2): inter- and intraobserver reliability assessment. J Neurosurg Spine 25(2): 256263.

17. Couture D, Avery N, Brockmeyer DL (2010) Occipitocervical instrumentation in the pediatric population using a custom loop construct: initial results and long-term follow-up experience. Neurosurg Pediatri 5(3): 285-291.

18. Fargen KM, Anderson RC, Harter DH, Angevine PD, Coon VC, et al (2011) Occipitocervicothoracic stabilization in pediatric patients. J Neurosurg Pediatr 8(1): 57-62.

19. Savage JG, Fulkerson DH, Sen AN, Thomas JG, Jea A (2014) Fixation with C-2 laminar screws in occipitocervical or C1-2 constructs in children 5 years of age or younger: a series of 18 patients. J Neurosurg Pediatr 14(1): 87-93.

20. Reintjes SL, Amankwah EK, Rodriguez LF, Carey CC, Tuite GF (2016) Allograft versus autograft for pediatric posterior cervical and occipitocervical fusion: a systematic review of factors affecting fusion rates. Journal of neurosurgery Pediatrics 17(2): 187-202.

21. Schultz KD, Petronio J, Haid RW, Rodts GE, Erwood SC, et al. (2000) Pediatric occipitocervical arthrodesis. A review of current options and early evaluation of rigid internal fixation techniques. Pediatr Neurosurg 33(4): 169-181

22. Ahmed R, Traynelis VC, Menezes AH (2008) Fusions at the craniovertebral junction. Child's Nerv Syst 24(10): 1209-1224.

23. Haque A, Price AV, Sklar FH, Swift DM, Weprin BE, et al. (2009) Screw fixation of the upper cervical spine in the pediatric population. Clinical article. J Neurosurg Pediatr 3(6): 529-533.

24. Sribnick EA, Dadashev VY, Brahma B, Wrubel DM (2012) The use of inside-outside screws for occipitocervical fusion in pediatric patients. J Neurosurg Pediatr 10(5): 392-397.

25. Gluf WM, Brockmeyer DL (2005) Atlantoaxial transarticular screw fixation: a review of surgical indications, fusion rate, complications, and lessons learned in 67 pediatric patients. J Neurosurg Spine 2(2): 164-169.

\section{Your next submission with Juniper Publishers will reach you the below assets}

- Quality Editorial service

- Swift Peer Review

- Reprints availability

- E-prints Service

- Manuscript Podcast for convenient understanding

- Global attainment for your research

- Manuscript accessibility in different formats

( Pdf, E-pub, Full Text, Audio)

- Unceasing customer service

Track the below URL for one-step submission

https://juniperpublishers.com/online-submission.php 